\title{
Tuberculosis Lymphadenitis in Association With Celiac Disease Mimicking Kikuchi-Fujimoto Disease
}

\author{
Naghi Dara ${ }^{1,}$; Abdollah Karimi ${ }^{2}$; Farid Imanzadeh ${ }^{1}$; Ali Amanati ${ }^{2}$; Ali Akbar Sayyari ${ }^{1}$; \\ Peyman Eshghi ${ }^{3}$ \\ ${ }_{2}^{1}$ Department of Pediatric Gastroenterohepatology, Mofid Children's Hospital, Shahid Beheshti University of Medical Sciences, Tehran, IR Iran \\ ${ }_{2}^{2}$ Pediatric Infections Research Center, Mofid Children's Hospital, Shahid Beheshti University of Medical Sciences, Tehran, IR Iran \\ ${ }^{3}$ Department of Pediatric Hematology Mofid Children's Hospital, Shahid Beheshti University of Medical Sciences, Tehran, IR Iran \\ ${ }^{*}$ Corresponding author: Naghi Dara, Department of Pediatric Gastroenterohepatology, Mofid Children's Hospital, Shahid Beheshti University of Medical Sciences, P. O. Box: 15468- \\ 15514, Tehran, IR Iran. Tel: +98-2122227028, Fax: +98-2122909128, E-mail: drdara49@yahoo.com
}

Received: August 23, 2014; Accepted: September 6, 2014

\begin{abstract}
Introduction: Kikuchi-Fujimoto disease (KFD) is an uncommon idiopathic self-limited cause of lymphadenitis that most commonly presents with cervical lymphadenopathy with or without systemic signs and symptom, which is also called histiocytic necrotizing lymphadenitis (1-6). Although infection and autoimmune etiology have been suggested, the cause of KFD is unknown. Several features that support a role for an infectious cause include the generally self-limited courses and association with symptoms similar to upper respiratory tract infection. Many viral infections have been proposed including cytomegalovirus, varicella zoster virus, human herpes virus, Epstein-Barr virus, parainfluenza virus, parvovirus B19, paramyxovirus, Yersinia enterocolitica, and Toxoplasma gondii. In a Korean study on 147 patients presenting at an outpatient clinic, KFD (34.7\%) and tuberculous (TB) adenitis (22.4\%) were the most common causes of cervical adenitis (7-14).

Case Presentation: We presented a case of TB lymphadenitis in association with celiac disease that mimicked KFD in a young child. Conclusions: Celiac disease, also known as gluten-sensitive enteropathy and nontropical sprue, is an autoimmune disease with chronic inflammation of small intestine, which is associated with increased risk of TB infection. TB lymphadenitis can mimic KFD. Therefore, in each case of unusual lymphadenitis, TB should be considered and if it is associated with failure to thrive, celiac disease should be suspected.
\end{abstract}

Keywords: Kikuchi Disease; Celiac Disease; Tuberculous Lymphadenitis; Necrotizing Lymphangitis; Young Child

\section{Introduction}

Kikuchi-Fujimoto disease (KFD), which was first diagnosed in japan, has been reported throughout the world and in all races, with most cases reported from East Asia fewer cases from Europe and North America. KFD is generally benign with self-limited course that typically affects young adults (mean age, 20-30 years). Females are affected more than males with a ratio of 3:1; moreover, disease in females occurs in a wide range of ages (2-75 years). KFD can be clinically and histologically mistaken with lymphoma or systemic lupus erythematosus. Several authors have reported an association between KFD with SLE. We report a case of TB lymphadenitis in association with celiac disease that mimicked KFD (15).

\section{Case Presentation}

The patient was a 16-year-old girl that was well up to six months ago. Then she presented with fever, weakness, malaise, anorexia, epigastric abdominal pain, nausea, and generalized variable-sized lymphadenopathy. In addition, she complained of headache, bone pain, diarrhea and $10 \mathrm{~kg}$ weight loss over six months. Her mother was a case of pulmonary tuberculosis (TB) and had received full course of anti-TB drugs two years ago. She had close contact with her mother. She was referred to our center for further evaluation.

\subsection{Physical Examination}

At the first visit, she was febrile with a temperature of $37.9^{\circ} \mathrm{C}$, pulse rate of $120 \mathrm{beat} / \mathrm{min}$, and blood pressure of 95/60 mm Hg. General appearance was cachectic and ill but nontoxic. Conjunctiva and nails were pale. She had multiple variable-sized lymph node in the cervical, submandibular, supraclavicular, auxiliary, and inguinal regions that some of them were tender with maximum size $19 \times 26 \mathrm{~mm}$. Abdomen was soft without organomegaly, but had vague tenderness without guarding or localized tenderness. Results of the central nervous system evaluation were insignificant.

She had microcytic hypochromic anemia, white blood cells of $4.3 \times 10^{9} / \mathrm{L}$ (polymorphonuclear cells, $70 \%$; and lymphocytes, 29\%), hemoglobin of $9.4 \mathrm{gr} / \mathrm{dL}$, mean corpuscular volume (MCV) of 65.3, mean corpuscular he-

Copyright (C) 2015, Pediartric Infections Research Center. This is an open-access article distributed under the terms of the Creative Commons Attribution-NonCommercial 4.0 International License (http://creativecommons.org/licenses/by-nc/4.0/) which permits copy and redistribute the material just in noncommercial usages, provided the original work is properly cited. 
moglobin (MCH) of $19 \mathrm{pg} / \mathrm{cell}$, mean corpuscular hemoglobin concentration (MCHC) of $291 \mathrm{~g} / \mathrm{L}$, red blood cells of $4.9 \times 10^{12} / \mathrm{L}$, platelet $545 \times 10^{9} / \mathrm{L}$, elevated erythrocyte sedimentation rate $(90 \mathrm{~mm} / \mathrm{h})$, and C-reactive protein of $30 \mathrm{nmol} / \mathrm{L}$. Other laboratory findings for serum aspartate aminotransferase, alanine aminotransferase, alkaline phosphatase, uric acid, lactate dehydrogenase, blood urea nitrogen, calcium, and creatinine were insignificant. In next step, excisional lymph node biopsy was done from two site of cervical and supraclavicular regions that revealed necrotizing granulomatous lymphadenitis suggestive for KFD. Thereafter, to rule out cause of lymphadenitis, acid fast staining was done on lymph node for detecting Mycobacterium specious, which yielded positive result. In addition, PCR on lymph nodes was positive for Mycobacterium tuberculosis. Results of virology studies for cytomegalovirus, human herpes viruses 6 and 8, Epstein-Barr virus, herpes simplex virus, and human immunodeficiency virus were negative. In addition, results of nitroblue tetrazolium (NBT), serum immunoglobulin electrophoresis, flow cytometery, dsDNA, lupus erythematosus cell (LE cell), C3, and C4 were in normal limits. Findings of the imaging study includes chest Xray were normal, No active infiltration was seen in lungs fields; however, high-resolution computed tomography showed multiple asymmetrical lymph nodes. The PPD test yielded positive results with $20 \mathrm{~mm}$ indurations.

Other imaging includes ultrasonography of abdomen and computed tomography findings were normal. Due to elevated anti-tTG-IgA to 73, EmA-IgA to 80, and positive HLA-DQ2, upper esophagogastroduodenoscopy with biopsy was done that revealed severe erythema in lower third of esophagus, mucosal erythema of gastric body, and erythematous mucosa of duodenum with atrophic villi. Biopsy confirms celiac disease as Marsh classification IIIC. Bone marrow aspiration revealed only increase in megakaryocyte. No malignant cell was seen. The patient was placed on gluten-free diet and standard anti-TB drugs (isoniazid, rifampin, ethambutol, and pyrazinamide) for six month and other supplementations including vitamin B6, calcium, vitamin D, and ferrous sulfate. During 18-months follow-up, she had good response to medication with corrected hemoglobin, increased appetite and weight, and resolved lymph nodes. The results of the latest PPD test was negative and anti-tTG Ab and EmA-Ab were in normal ranges.

\section{Discussion}

Celiac disease, also known as gluten-sensitive enteropathy and nontropical sprue, is an autoimmune disease with chronic inflammation of small intestine because of specific immunologic response to gluten proteins in wheat, barley, and rye, which leads to villous atrophy. Celiac disease is common in the white population with prevalence of approximately $0.5 \%$ to $1 \%(16,17)$. Clinical presentation of celiac disease may be asymptomatic (silent) or has wide spectrum (classic form) including chronic diar- rhea, abdominal distension, abdominal pain, anorexia, iron deficiency anemia, constipation, symptoms of intestinal malabsorption such as malnutrition and failure to thrive (18-21). Celiac disease is associated with a number of complications including malignant lymphoma and autoimmune disorders.

TB affects a large proportion of the world population and is more common in individuals with malnutrition. Mycobacterium tuberculosis infects about one-third of the world's population, although active TB is less common (6). TB can affect any part of the body but most often involves the lungs, where it causes tissue destruction. Several researches have suggested a positive association between celiac disease and TB.

In the large cohort study by Ludvigsson et al. (18) celiac disease was associated with an increased risk of TB infection (hazard ratio [HR], 3.74; 95\% CI, 2.14-6.53; and P = $0.001)$. Similar risk estimates were seen when the population was stratified for sex and age at celiac disease diagnosis. Patients with celiac disease had also more probability of making the diagnosis of TB in departments of pulmonary medicine, infectious diseases, pediatrics, or thoracic medicine (HR, 4.76; 95\% CI 2.23-10.16; and P $=0.001)$. The odds ratio for celiac disease in individuals with prior TB was 2.50 (95\% CI, 1.75-3.55; $\mathrm{P}=0.001)$ (22). In this study, celiac disease was associated with three- to four-fold increase in the risk of developing TB; the malnutrition associated with celiac disease, particularly vitamin D deficiency, might perform an important role in the increased risk of TB. Individuals with celiac disease were at increased risk of TB (HR, 2.0; 95\% CI, 1.3-3.0); during follow-up, 31 individuals with celiac disease and 74 reference individuals had a diagnosis of TB (23). Peters et al. found a six-fold increase in the risk of death from TB in individuals with celiac disease (24).

In another study, several cases of TB lymphadenitis presented similar to $\operatorname{KFD}(25,26)$. This case demonstrates the coexistence of mycobacterial lymphadenitis and histiocytic necrotizing lymphadenitis in the patient with celiac disease. However, it is unclear whether this represents a coincidental event or whether the infection agent causing unusual immune response leads to histiocytic necrotizing lymphadenitis. Therefore, additional evidence is necessary to link these two entities to define their relationship. In an unusual presentation of KFD, infection with TB and celiac disease should be considered.

\section{Authors' Contributions}

Dr. Naghi Dara: study design, literature search, drafting, and review of the manuscript. Dr. Abdollah Karimi. Study design, supervision, and review of manuscript. Dr. Ali Amanati, Dr. Farid Imanzadeh, Dr. Ali Akbar Sayyari, and Dr. Peyman Eshghi were teamwork in concept.

\section{References}

1. Kampitak T. Fatal Kikuchi-Fujimoto disease associated with SLE 
Dara $N$ et al.

and hemophagocytic syndrome: a case report. Clin Rheumatol. 2008;27(8):1073-5.

2. Singh YP, Agarwal V, Krishnani N, Misra R. Enthesitis-related arthritis in Kikuchi-Fujimoto disease. Mod Rheumatol. 2008;18(5):492-5.

3. Bosch X, Guilabert A, Miquel R, Campo E. Enigmatic KikuchiFujimoto disease: a comprehensive review. Am J Clin Pathol. 2004;122(1):141-52.

4. Lin HC, Su CY, Huang CC, Hwang CF, Chien CY. Kikuchi's disease: a review and analysis of 61 cases. Otolaryngol Head Neck Surg. 2003;128(5):650-3.

5. Baumgartner BJ, Helling ER. Kikuchi's disease: a case report and review of the literature. Ear Nose Throat J. 2002;81(5):331-5.

6. Kuo TT. Kikuchi's disease (histiocytic necrotizing lymphadenitis). A clinicopathologic study of 79 cases with an analysis of histologic subtypes, immunohistology, and DNA ploidy. Am J Surg Pathol.1995;19(7):798-809.

7. Yen A, Fearneyhough P, Raimer SS, Hudnall SD. EBV-associated Kikuchi's histiocytic necrotizing lymphadenitis with cutaneous manifestations. J Am Acad Dermatol. 1997;36(2 Pt 2):342-6.

8. Hudnall SD, Chen T, Amr S, Young KH, Henry K. Detection of human herpesvirus DNA in Kikuchi-Fujimoto disease and reactive lymphoid hyperplasia. Int J Clin Exp Pathol. 2008;1(4):362-8.

9. Huh J, Kang GH, Gong G, Kim SS, Ro JY, Kim CW. Kaposi's sarcoma-associated herpesvirus in Kikuchi's disease. Hum Pathol. 1998;29(10):1091-6.

10. Yufu Y, Matsumoto M, Miyamura T, Nishimura J, Nawata $\mathrm{H}$ Ohshima K. Parvovirus B19-associated haemophagocytic syndrome with lymphadenopathy resembling histiocytic necrotizing lymphadenitis (Kikuchi's disease). Br I Haematol. 1997;96(4):868-71.

11. Chiu CF, Chow KC, Lin TY, Tsai MH, Shih CM, Chen LM. Virus infection in patients with histiocytic necrotizing lymphadenitis in Taiwan. Detection of Epstein-Barr virus, type I human T-cell lymphotropic virus, and parvovirus B19. Am J Clin Pathol. 2000;113(6):774-81.

12. Hudnall SD. Kikuchi-Fujimoto disease. Is Epstein-Barr virus the culprit? Am JClin Pathol. 2000;113(6):761-4.

13. Rich SA. De novo synthesis and secretion of a $36-\mathrm{kD}$ protein by cells that form lupus inclusions in response to alpha-interferon. J Clin Invest. 1995;95(1):219-26.
14. Iguchi H, Sunami K, Yamane H, Konishi K, Takayama M, Nakai Y et al. Apoptotic cell death in Kikuchi's disease: a TEM study. Acta Otolaryngol Suppl.1998;538:250-3.

15. Song JY, Cheong HJ, Kee SY, Lee J, Sohn JW, Kim MJ, et al. Disease spectrum of cervical lymphadenitis: analysis based on ultrasound-guided core-needle gun biopsy.J Infect. 2007;55(4):310-6.

16. Green PH, Jabri B. Coeliac disease. Lancet. 2003;362(9381):383-91.

17. Dube C, Rostom A, Sy R, Cranney A, Saloojee N, Garritty C, et al. The prevalence of celiac disease in average-risk and at-risk Western European populations: a systematic review. Gastroenterology. 2005;128(4 Suppl 1):S57-67.

18. Ludvigsson JF, Ansved P, Falth-Magnusson K, Hammersjo JA, Johansson C, Edvardsson S, et al. Symptoms and signs have changed in Swedish children with coeliac disease. J Pediatr Gastroenterol Nutr. 2004;38(2):181-6.

19. Askling J, Linet M, Gridley G, Halstensen TS, Ekstrom K, Ekbom A. Cancer incidence in a population-based cohort of individuals hospitalized with celiac disease or dermatitis herpetiformis. Gastroenterology. 2002;123(5):1428-35.

20. Collin P, Reunala T, Pukkala E, Laippala P, Keyrilainen O, Pasternack A. Coeliac disease--associated disorders and survival. Gut. 1994;35(9):1215-8.

21. Ludvigsson JF, Montgomery SM, Ekbom A. Celiac disease and risk of adverse fetal outcome: a population-based cohort study. Gastroenterology. 2005;129(2):454-63.

22. Ludvigsson JF, Wahlstrom J, Grunewald J, Ekbom A, Montgomery SM. Coeliac disease and risk of tuberculosis: a population based cohort study. Thorax. 2007;62(1):23-8.

23. Ludvigsson JF, Sanders DS, Maeurer M, Jonsson J, Grunewald J, Wahlstrom J. Risk of tuberculosis in a large sample of patients with coeliac disease--a nationwide cohort study. Aliment Pharmacol Ther. 2011;33(6):689-96.

24. Peters U, Askling J, Gridley G, Ekbom A, Linet M. Causes of death in patients with celiac disease in a population-based Swedish cohort. Arch Intern Med. 2003;163(13):1566-72.

25. Jayaraj SM, Lloyd J, Frosh AC, Patel KS. Kikuchi-Fujimoto's syndrome masquerading as tuberculosis. J Laryngol Otol. 1999;113(1):82-4.

26. Elendu S, Rhaman HM, Fleischman JK. Histiocytic Necrotizing lymphadenitis and tuberculosis infection in the same lymph node a case report. Hosp Physician. 2003:53-6. 